\title{
Effect of the thermoplastic masks on dose distribution in the build-up region for photon beams
}

\author{
Michał Półtorak $^{1 \mathrm{a}}$, Edyta Fujak ${ }^{1}$, Paweł Kukołowicz ${ }^{1}$ \\ ${ }^{I}$ Cancer Center-Institute of Oncology, Wawelska 15B, Warsaw \\ ${ }^{a}$ E-mail address: michalmichalpp@gmail.com
}

\begin{abstract}
The aim of the study was to investigate the influence of thermoplastic masks material (Klarity Medical\&Equipment Co., Guangzhou, China) with different diameters of holes $(\phi 0.25 \mathrm{~cm}$ and $\phi 0.40 \mathrm{~cm})$ on the dose distribution in the build-up region for photon beams. Measurements were made for external radiation beams produced by the linear accelerator (TrueBeam, Varian Medical Systems, Inc., Palo Alto, CA, USA) using the Markus parallel plane ionization chamber and the Unidos electrometer (both from PTW, Freiburg, Germany). Measurements were made in a solid water phantom for two photon energies $6 \mathrm{MV}$ and $15 \mathrm{MV}$, at $90 \mathrm{~cm}$ source to skin distance, for four fields of $5 \mathrm{~cm} \times 5 \mathrm{~cm}$, $10 \mathrm{~cm} \times 10 \mathrm{~cm}, 15 \mathrm{~cm} \times 15 \mathrm{~cm}$ and $20 \mathrm{~cm} \times 20 \mathrm{~cm}$. Compared to the open field, the maximum dose with mask was closer to the surface of the phantom by about $1.4 \mathrm{~mm}$ and $1.2 \mathrm{~mm}$ for $6 \mathrm{MV}$ and $15 \mathrm{MV}$ X-Rays, respectively. The surface dose increase from $10 \%$ to $42 \%$ for $6 \mathrm{MV}$ and from $5 \%$ to $28 \%$ for $15 \mathrm{MV}$ X-Rays.
\end{abstract}

Key words: radiotherapy; thermoplastic mask; X-ray; percentage depth dose; AAPM TG 176.

\section{Introduction}

Thermoplastic masks are mainly used in the head\&neck region to ensure the good reproducibility of the patients position during fractionated radiotherapy. In general the surface dose is considerably increased and the position of the maximum dose is reached at a shallower depth. From a clinical point of view these changes lead to the increase of radiation-induced skin reactions, which is the disadvantage of a masks implementation [1]. It's important that skin doses over about 25 Gy at 2 Gy per fraction produce clinically relevant skin reactions and greater than 45 Gy may produce dry desquamation [2]. However, in the certain situations masks play a role of the bolus, which may help in delivering the full dose to malignant tissue located very close to the skin surface. Regardless, the use of masks is beneficial or not, the knowledge of the influence is helpful in clinical practice. There are various commercially available thermoplastic masks produced by different manufactures. They have different thickness and holes diameters. In this study the purpose was to investigated the influence of two types of unstretched thermoplastic masks offered by the Klarity company (Klarity Medical\&Equipment Co., Guangzhou, China) on the dose distribution for photon beams (6 MV and $15 \mathrm{MV}$ ) delivered through flattering filter.

\section{Materials and Methods}

The influence of masks on a dose distribution was investigated for two different unstretched samples with hole sizes of $\phi 0.25 \mathrm{~cm}$ and $\phi 0.40 \mathrm{~cm}$ diameters (figure 1). Both samples had thickness of $2 \mathrm{~mm}$. The percentage depth dose (PDD) for two $\mathrm{x}$-rays photon beam (6 MV and $15 \mathrm{MV}$ ) delivered through flattering filter were measured respectively for setup with and without mask material. All measurements were performed on the TrueBeam accelerator (Varian Medical Systems, Inc., Palo Alto, CA, USA) in solid water equivalent phantom. The data was collected with the Markus parallel plate ionization chamber (ref. no. 23343, PTW, Freiburg, Germany) and the Unidos electrometer (PTW, Freiburg, Germany). Figure 2 shows the measurement set-up used in this study.

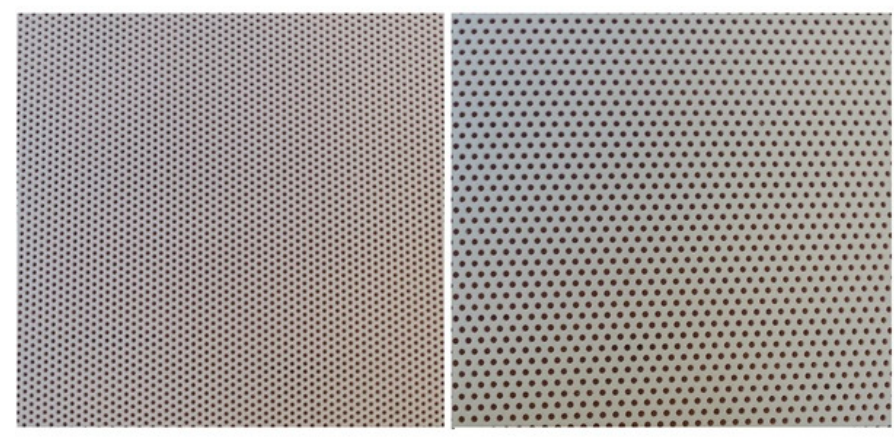

Figure 1. The sample masks with hole sizes of $\phi 0.25 \mathrm{~cm}$ (left) and $\phi 0.40 \mathrm{~cm}$ diameters (right).

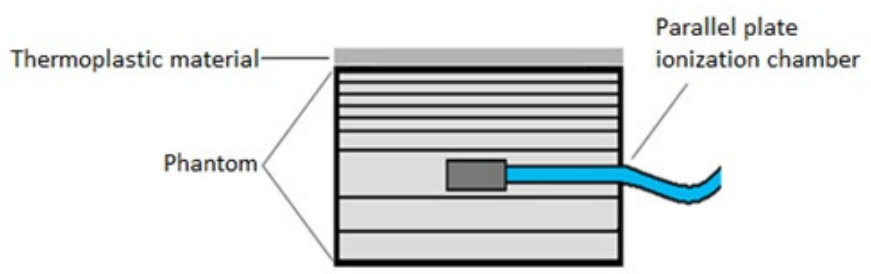

Figure 2. The measurement set-up. 
The source skin distance (SSD) was $90 \mathrm{~cm}$. The PDD measurements were performed for four square fields of $5 \mathrm{~cm} \mathrm{x}$ $5 \mathrm{~cm}, 10 \mathrm{~cm} \times 10 \mathrm{~cm}, 15 \mathrm{~cm} \times 15 \mathrm{~cm}$ and $20 \mathrm{~cm} \times 20 \mathrm{~cm}$. The dose was measured with the resolution of 1 millimeter in depth range from 0 to $30 \mathrm{~mm}$, and with a spacing of $5 \mathrm{~mm}$ at larger depths ranged from 30 to $60 \mathrm{~mm}$. Each measurement was repeated three times. Percentage dose depth was determined by using the equation $1[3,4]$.

$\operatorname{PDD}(\mathrm{d}, \mathrm{A}, \mathrm{SSD}, \mathrm{E})=\frac{\mathrm{D}(\mathrm{d})}{\mathrm{D}\left(\mathrm{d}_{\max }\right)} \times 100 \%$

Eq. 1

where d - depth of measurement, A - radiation field size, SSD Source Skin Distance, E - energy, D(d) - dose at depth d, $\mathrm{D}\left(\mathrm{d}_{\max }\right)$ - the maximum dose.

The inaccuracies in the measurement of dose in the buildup region when using Markus chamber are well known. Ideally extrapolation chamber or well-guarded fixed separation planeparallel chamber should be used. The Markus chamber has narrow guard-ring causing perturbation of the electron fluence through the chamber side wall and significant overresponse in build-up region. Therefore, all results were corrected by the formula proposed by Gerbi and Khan (equation 2). [5-7]:

$\Delta \mathrm{PDD}=\left[27.19-32.59 \cdot \mathrm{TPR}_{10}^{20}+\mathrm{C} \cdot(-1.666+1.982 \cdot\right.$

$\left.\left.\mathrm{TPR}_{10}^{20}\right)\right] \cdot \mathrm{L} \cdot \mathrm{e}^{\left(-5.5 \cdot \frac{\mathrm{d}}{\mathrm{d}_{\max }}\right)}$

Eq. 2

where $\mathrm{TPR}_{10}^{20}$ - parameter specifying the quality of the radiation beam, C - guard-ring width, L - the height of the air cavity, $\mathrm{d}$ depth of measurement, $d_{\max }$ - the depth of maximum dose. In our case $\mathrm{TPR}_{10}^{20}$ for $6 \mathrm{MV}$ was equal to 0.669 and for $15 \mathrm{MV}$ was equal to 0.763 . For Markus chamber (23343) $\mathrm{C}=0.2 \mathrm{~mm}$ and $\mathrm{L}=2 \mathrm{~mm}$.

To correct PDD data points the four parameter function $D\left(D_{0}, \mu_{1}, \mu_{2}, d_{0}\right)$ was fitted using the least square method (equation 3).

$D=D_{0} \cdot e^{\left(-\mu_{1} \cdot d\right)} \cdot\left(1-e^{\left(-\mu_{2}\left(d+\sqrt{d}-d_{0}\right)\right)}\right)$

Eq. 3

where $D_{0}$ - constant, describing the dose on the surface, $\mu_{1}$ parameter responsible for the PDD at depths larger than depth of maximum dose, $\mu_{2}$ - parameter responsible for the PDD in the build-up region, $\mathrm{d}$ - depth, $\mathrm{d}_{0}$ - constant.

\section{Results}

Figures 3 and 4 show the percentage depth dose measured for the square field size of $5 \mathrm{~cm} \times 5 \mathrm{~cm}$ when the thermoplastic material with small and big holes $(\phi 0.25 \mathrm{~cm}$ and $\phi 0.40 \mathrm{~cm})$ was placed on the phantom surface for energies $6 \mathrm{MV}$ and $15 \mathrm{MV}$, respectively. The results indicate an unnoticeable influence of a hole diameter on the dose distribution for $6 \mathrm{MV}$ and a very small difference for $15 \mathrm{MV}$ at the depths from $0 \mathrm{~mm}$ to $10 \mathrm{~mm}$.

Similar results were obtained for square field sizes of $10 \mathrm{~cm}$ x $10 \mathrm{~cm}, 15 \mathrm{~cm}$ x $15 \mathrm{~cm}$ and $20 \mathrm{~cm} \mathrm{x} 20 \mathrm{~cm}$. Non-significant differences between the results obtained for two kinds of masks. It allows us to further presentation the results obtained for one kind of mask.
Figure 5 and 6 show a comparison of percentage depth dose measured for a field size $5 \mathrm{~cm}$ x $5 \mathrm{~cm}$, for masks with large holes $(\phi 0.40 \mathrm{~cm})$ and without masks, for X-ray energy of $6 \mathrm{MV}$ and $15 \mathrm{MV}$.

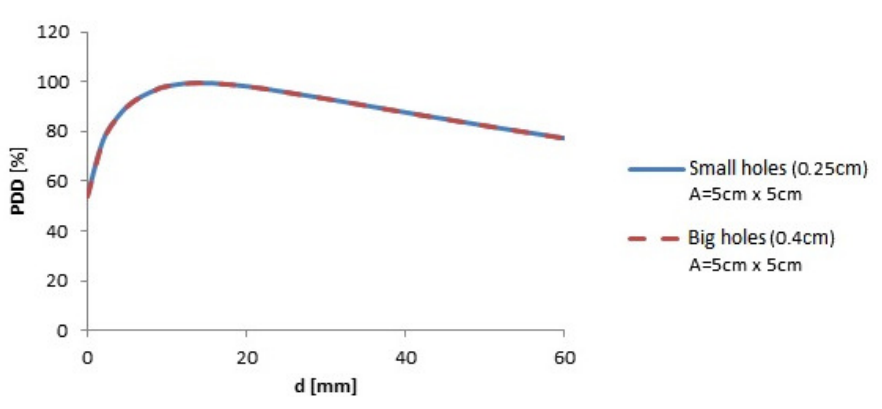

Figure 3. The PDD for the masks with hole diameters of $\phi 0.25 \mathrm{~cm}$ and $\phi 0.40 \mathrm{~cm}$, for $6 \mathrm{MV}$. Results for square field of $5 \mathrm{~cm} \times 5 \mathrm{~cm}$ are presented.

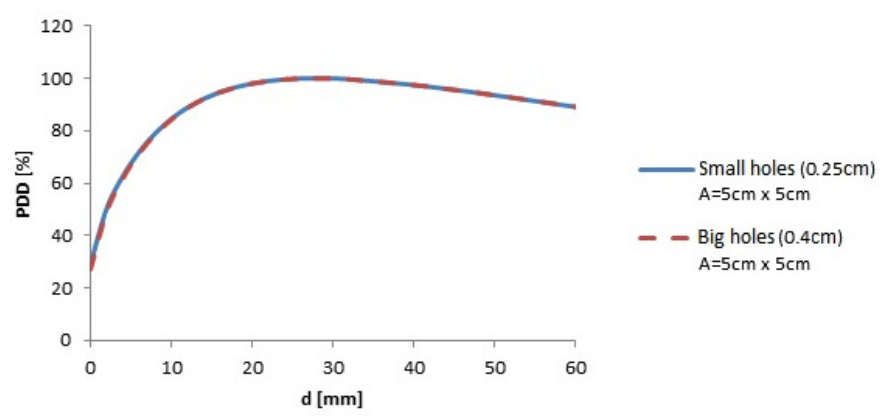

Figure 4. The PDD for the masks with hole diameters of $\phi 0.25 \mathrm{~cm}$ and $\phi 0.40 \mathrm{~cm}$, for $15 \mathrm{MV}$. Results for square field of $5 \mathrm{~cm} \times 5 \mathrm{~cm}$ are presented.

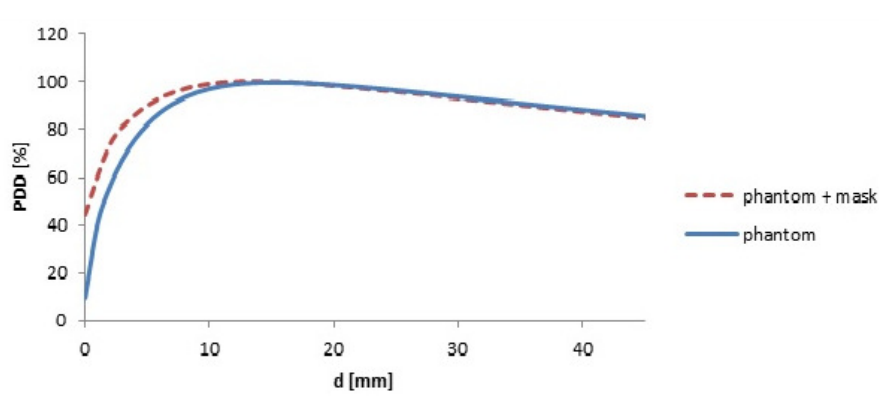

Figure 5. The comparison of PDD measured with a mask $(\phi=0.40$ $\mathrm{cm})$ and without a mask for $6 \mathrm{MV}$ photon beam.

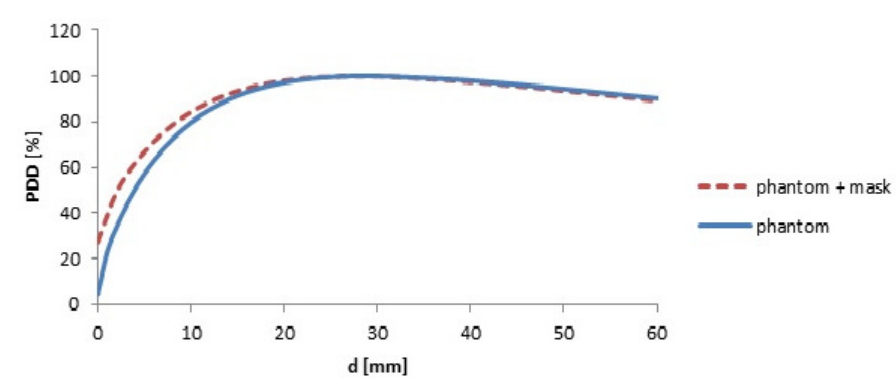

Figure 6. The comparison of PDD measured with a mask $(\phi=0.40$ $\mathrm{cm})$ and without a mask for $15 \mathrm{MV}$ photon beam. 
Table 1. The surface dose.

\begin{tabular}{lccccc}
\hline \hline \multirow{2}{*}{ Set-up } & \multirow{2}{*}{$\begin{array}{c}\text { Energy } \\
{[\mathbf{M V}]}\end{array}$} & \multicolumn{4}{c}{ Dose on the surface [\%] for field A $\left[\mathbf{c m}^{2}\right]$} \\
\cline { 3 - 6 } & $\mathbf{A = 5 x 5}$ & $\mathbf{A = 1 0 x 1 0}$ & $\mathbf{A = 1 5 x 1 5}$ & $\mathbf{A = 2 0 x 2 0}$ \\
\hline Phantom & $6 \mathrm{MV}$ & 10 & 17 & 20 & 26 \\
\hline $\begin{array}{l}\text { Phantom } \\
+ \text { Mask }\end{array}$ & $6 \mathrm{MV}$ & 42 & 48 & 52 & 58 \\
\hline $\begin{array}{l}\text { Phantom } \\
\text { Phantom }\end{array}$ & $15 \mathrm{MV}$ & 5 & 12 & 20 & 28 \\
\hline \begin{tabular}{l} 
+Mask \\
\hline
\end{tabular} & $15 \mathrm{MV}$ & 28 & 34 & 41 & 52 \\
\hline
\end{tabular}

Table 2. The depths of $70 \%, 90 \%$ and depths of maximum dose.

\begin{tabular}{|c|c|c|c|c|c|c|}
\hline \multirow{2}{*}{ Set-up } & \multirow{2}{*}{$\begin{array}{c}\text { Energy } \\
{[\mathrm{MV}]}\end{array}$} & \multirow{2}{*}{ PDD [\%] } & \multicolumn{4}{|c|}{ Depth of PDD [mm] for field A $\left[\mathrm{cm}^{2}\right]$} \\
\hline & & & $A=5 \times 5$ & $A=10 \times 10$ & $A=15 \times 15$ & $A=20 \times 20$ \\
\hline \multirow{3}{*}{ Phantom } & \multirow{3}{*}{$6 \mathrm{MV}$} & $70 \%$ & 3.5 & 3.0 & 2.5 & 2.0 \\
\hline & & $90 \%$ & 7.0 & 6.5 & 6.0 & 5.5 \\
\hline & & $100 \%$ & 15.2 & 14.9 & 14.5 & 13.9 \\
\hline \multirow{3}{*}{$\begin{array}{c}\text { Phantom } \\
\text { + Mask }\end{array}$} & \multirow{3}{*}{$6 \mathrm{MV}$} & $70 \%$ & 2.0 & 1.5 & 1.0 & 0.5 \\
\hline & & $90 \%$ & 5.5 & 5.0 & 4.5 & 4.0 \\
\hline & & $100 \%$ & 13.6 & 13.5 & 13.1 & 12.9 \\
\hline \multirow{3}{*}{ Phantom } & \multirow{3}{*}{$15 \mathrm{MV}$} & $70 \%$ & 8.0 & 6.5 & 5.5 & 4.5 \\
\hline & & $90 \%$ & 14 & 12 & 11 & 9.5 \\
\hline & & $100 \%$ & 29.2 & 27.2 & 25.1 & 23.1 \\
\hline \multirow{3}{*}{$\begin{array}{c}\text { Phantom } \\
\text { + Mask }\end{array}$} & \multirow{3}{*}{$15 \mathrm{MV}$} & $70 \%$ & 7.0 & 5.5 & 4.5 & 3.5 \\
\hline & & $90 \%$ & 13 & 11 & 10 & 8.5 \\
\hline & & $100 \%$ & 27.9 & 26.4 & 23.9 & 22.1 \\
\hline
\end{tabular}

In table 1 the surface doses for fields with a mask and without a mask for all square fields and for $6 \mathrm{MV}$ and $15 \mathrm{MV}$ are given. In table 2, the depths of 70\%, $90 \%$ and the depth of $\mathrm{d}_{\max }$ measured with and without a mask for all fields and both energies are given. Measurement uncertainties shifts are respectively $0.5 \mathrm{~mm}$.

\section{Discussion}

The purpose of this study was to investigate the effect of thermoplastic masks on the dose distribution in the build-up region of photon beams. As we show, the usage of thermoplastic masks slightly increases the therapeutic area located directly below the surface of the body. Due to the increase of the dose in the build-up region, the use of thermoplastic masks will result in increased radiation skin reactions. These reactions are uncontrolled when the mask is not included during the planning process. The planned doses in the skin area are inaccurate and significantly differ from the doses delivered during radiation therapy.

Our study was targeted on the specific product developed by Klarity Company. Therefore, the surface dose for Klarity masks increases respectively for $6 \mathrm{MV}$ from $10 \%$ to $42 \%$ and for $15 \mathrm{MV}$ from $5 \%$ to $28 \%$, irrespective of the field size. Moreover, the maximum of the percentage depth dose occurs closer to the surface, in case of using thermoplastic material. For $6 \mathrm{MV}$, the average value by which the dose has been shifted (in the entire area of the build-up region) towards the surface was $1.4 \mathrm{~mm}$, in turn for the energy of $15 \mathrm{MV}$ it amounted to $1.2 \mathrm{~mm}$. This shifting effect could be used positively for simple radiotherapy techniques (e.g. two opposite beams) when mask is included during planning process. For example, the $90 \%$ (PDD) isodose is reached at a depth of about $1 \mathrm{~mm}$ shallower, compared to the situation without mask. This may help in delivering the full-prescribed dose for targets located very superficially, however this dose increase may not always be sufficient.

Other important observation is, that $2 \mathrm{~mm}$ thickness of mask delivered by Klarity Company does not change the shape of the percentage depth curves. The dose increases rapidly and then slowly decreases. Our study shows that different hole diameters (e.g. $\phi 0.25 \mathrm{~cm}$ and $\phi 0.40 \mathrm{~cm}$ ) of thermoplastic material, have a very small influence on the characteristics of the percentage depth dose curve. Therefore we recommend the masks with a smaller diameter of the hole due to the increased stiffness and thus, better immobilization properties.

\section{Conclusions}

The use of a thermoplastic mask slightly increases the therapeutic area located directly below the surface of the body. The surface dose for Klarity masks increases respectively for $6 \mathrm{MV}$ from $10 \%$ to $42 \%$ and for $15 \mathrm{MV}$ from $5 \%$ to $28 \%$, irrespective of the field size. The smaller $(\phi 0.25 \mathrm{~cm})$ and larger holes $(\phi 0.40 \mathrm{~cm})$ in investigated masks material affect the depth dose distribution in a comparable way.

\section{References}

[1] Lee N, Chuang C, Quivey JM, et al. Skin toxicity due to intensity-modulated radiotherapy for head-and-neck carcinoma. Int J Radiat Oncol Biol Phys. 2002;53(3):630-637.

[2] Olch AJ, Gerig L, Li H, et al. Dosimetric effects caused by couch tops and immobilization devices: Report of AAPM Task Group 176. Med Phys. 2014;41(6):061501.

[3] Wittych J, Kukołowicz P. Effect of beam spoiler on radiation dose in the build-up region for 6-MV X-ray. Rep Prac Oncol Radiother. 2003;8(1):15-23.

[4] Kukołowicz P. Charakterystyka wiązek terapeutycznych fotonów i elektronów. Kielce, 2001.

[5] Gerbi BJ, Khan FM. Measurement of dose in the buildup region using fixed-separation plane-parallel ionization chambers. Med Phys. 1990;17(1):17-24. 
[6] Velkley DE, Manson DJ, Purdy JA, Oliver GD Jr. Build-up region of megavoltage photon radiation sources. Med Phys. 1975;2(1):14-19.

[7] Apipunyasopon L, Srisatit S, Phaisangittiskul N. An investigation of the depth dose in the build-up region, and surface dose for a 6-MV therapeutic photon beam: Monte Carlo simulation and measurements. J Radiat Res. 2013;54(2):374-382.

\section{Appendix}

Table 3. Provides a summary of four fitting parameters with errors, to the equation 3.

\begin{tabular}{|c|c|c|c|c|c|c|c|c|c|}
\hline Set-up & Energy $[\mathrm{MV}] \mid$ File size $\left[\mathrm{cm}^{2}\right]$ & $\mathbf{D}_{0}$ & $\Delta \mathbf{D}_{0}$ & $\mu_{1}$ & $\Delta \mu_{1}$ & $\mu_{2}$ & $\Delta \mu_{2}$ & $\mathbf{d}_{0}$ & $\Delta \mathbf{x}_{0}$ \\
\hline \multirow{4}{*}{ Phantom } & $6 \mathrm{MV} \mathrm{A}=5 \times 5$ & 113.0 & 0.2 & 0.00618 & 0.00005 & 0.179 & 0.001 & -0.49 & 0.02 \\
\hline & $6 \mathrm{MV} \mathrm{A}=10 \times 10$ & 111.1 & 0.2 & 0.00545 & 0.00005 & 0.187 & 0.002 & -0.78 & 0.02 \\
\hline & $6 \mathrm{MV} \mathrm{A}=15 \times 15$ & 110.0 & 0.2 & 0.00504 & 0.00005 & 0.197 & 0.002 & -1.06 & 0.03 \\
\hline & $6 \mathrm{MV} \mathrm{A}=20 \times 20$ & 109.1 & 0.2 & 0.00479 & 0.00005 & 0.204 & 0.002 & -1.34 & 0.03 \\
\hline \multirow{4}{*}{$\begin{array}{l}\text { Phantom } \\
+ \text { Mask }\end{array}$} & $6 \mathrm{MV} \mathrm{A}=5 \times 5$ & 112.8 & 0.8 & 0.0064 & 0.0002 & 0.169 & 0.005 & -2.97 & 0.09 \\
\hline & $6 \mathrm{MV} \mathrm{A}=10 \times 10$ & 110.7 & 0.7 & 0.0056 & 0.0002 & 0.178 & 0.005 & -3.24 & 0.10 \\
\hline & $6 \mathrm{MV} \mathrm{A}=15 \times 15$ & 109.6 & 0.7 & 0.0052 & 0.0002 & 0.183 & 0.006 & -3.56 & 0.11 \\
\hline & $6 \mathrm{MV} \mathrm{A}=20 \times 20$ & 108.3 & 0.5 & 0.0048 & 0.0002 & 0.196 & 0.005 & -3.73 & 0.10 \\
\hline \multirow{4}{*}{ Phantom } & $15 \mathrm{MV} \mathrm{A}=5 \times 5$ & 121.8 & 0.7 & 0.00495 & 0.00009 & 0.086 & 0.001 & -0.46 & 0.04 \\
\hline & $15 \mathrm{MV} A=10 \times 10$ & 118.8 & 0.6 & 0.00462 & 0.00010 & 0.092 & 0.001 & -1.23 & 0.05 \\
\hline & $15 \mathrm{MV} \mathrm{A}=15 \times 15$ & 116.2 & 0.5 & 0.00439 & 0.00008 & 0.101 & 0.001 & -1.88 & 0.05 \\
\hline & $15 \mathrm{MV} \mathrm{A}=20 \times 20$ & 114.3 & 0.4 & 0.00425 & 0.00008 & 0.111 & 0.001 & -2.45 & 0.06 \\
\hline \multirow{4}{*}{$\begin{array}{l}\text { Phantom } \\
+ \text { Mask }\end{array}$} & $15 \mathrm{MV} \mathrm{A}=5 \times 5$ & 122.9 & 1.1 & 0.0053 & 0.0001 & 0.078 & 0.002 & -3.22 & 0.11 \\
\hline & $15 \mathrm{MV} \mathrm{A}=10 \times 10$ & 118.8 & 1.0 & 0.0047 & 0.0001 & 0.086 & 0.002 & -3.97 & 0.14 \\
\hline & $15 \mathrm{MV} \mathrm{A}=15 \times 15$ & 115.9 & 0.7 & 0.0045 & 0.0001 & 0.096 & 0.002 & -4.62 & 0.14 \\
\hline & $15 \mathrm{MV} \mathrm{A}=20 \times 20$ & 114.9 & 0.7 & 0.0045 & 0.0001 & 0.096 & 0.002 & -6.22 & 0.14 \\
\hline
\end{tabular}

